\title{
Comparison of E-Learning, M-Learning and Game-based Learning in Programming Education
}

\author{
A Gendered Analysis \\ https://doi.org/10.3991/ijet.v15i15.14503 \\ Sohail Iqbal Malik ( ${ }^{\bowtie}$, Mostafa Al-Emran, Roy Mathew \\ Al-Buraimi University College, Al-Buraimi, Oman \\ sohail@buc.edu.om \\ Ragad M Tawafak \\ Al-Buraimi University College, Al-Buraimi, Oman \\ University Malaysia Pahang, Kuantan, Malaysia \\ Ghaliya AlFarsi \\ Al-Buraimi University College, Al-Buraimi, Oman
}

\begin{abstract}
Learning to code is considered as a difficult and challenging task for a significant number of novice programmers in programming education. Novice programmers have to acquire different skills such as problem solving, program design, comprehension, and debugging at the same time. On the other hand, most introductory programming courses focus more on syntax of the programming language. In this study, we developed and introduced a 'PROBSOL' application in three different learning systems (E-learning, M-learning and Game-based learning) to enhance the problem solving skills of novice programmers in an introductory programming (IP) course. A survey was conducted with the IP students to determine their perception about all the three applications in the IP course. Gender differences were determined by comparing both female and male students' responses for each question in the survey. The results of comparison show that male students were more satisfied with all the three applications compared to female students. Both female and male students perceived that all the three applications are user-friendly, enabled them to accomplish tasks more quickly, and enhanced their learning productivity. Overall, both male and female students appreciated all the three applications in the teaching and learning process of the IP course. This study implies that instructors can also use all the three applications as an additional teaching tool in the teaching and learning process of programming education.
\end{abstract}

Keywords-Learning to code, problem solving skills, programming education, E-learning, M-learning, Game-based learning. 


\section{Introduction}

Learning to code is considered as a difficult and challenging task for a considerable number of novices in computer science and related disciplines [1][2]. The traditional approach used in the introductory programming courses focuses more on programming knowledge (syntax and semantics) instead of paying equal attention to problem solving strategies [3]. As a result, reference [4] argued 'that novice programmers know the syntax and semantics of individual statements, but they do not know how to combine these features into valid programs' (p. 17). Therefore, problem solving skills should be offered for the whole semester for novices in an introductory programming course [5].

In this study, we developed and introduced the 'PROBSOL' application in three different learning systems (E-learning, M-learning and Game-based learning) to enhance the problem solving skills of novice programmers. Most of the teaching topics of the IP course are covered in these three applications. Hence, these applications offer problem solving skills to novices for the whole semester.

This paper is divided into a number of sections. It starts with a literature review, followed by research questions. A brief introduction to the 'E-PROBSOL, MPROBSOL, and PROSOLVE' game is provided. The research methodology is described for this study, and research results are reported and discussed. The paper concludes with a summary of the outcomes.

\section{$2 \quad$ Literature Review}

Computer programming skills are one of the core competencies expected from graduates of computer science and related discipline [6]. On the other side, it is considered as a difficult and challenging task for novice programmers to acquire these skills [7]. Reference [8] argued that introductory programming courses focus more on syntax of the programming language instead of paying equal to problem solving strategies as well. Different teaching strategies and methods are introduced in the introductory programming courses to address this issue.

Reference [6] introduced a facilitative E-learning system, PASS (Programming Assignment Assessment System), to facilitate novices in learning programming. In PASS, an instructor uploads a programming problem along with a set of test cases. A student solves the problem and submits the solution to the system. The system automatically assesses the solution against the test cases submitted by the instructor and provides instant feedback to the student. Therefore, PASS uses a stepwise-reflective approach for novices to learn programming and provides students timely and relevant feedback to facilitate their learning process.

Reference [9] introduced M-learning in an introductory programming course and discussed that overwhelming majority of students appreciated the M-learning in the teaching and learning process of the course. Reference [10] also introduced Mlearning in the teaching and learning process and concluded that the retention of specific subject knowledge in first year university students for a mobile learning group 
was better than the other group without offering this option. Reference [11] discussed 'how smartphones, studio-based learning and extensive scaffolding could be used in combination in teaching of a freshman introduction to programming course' (p. 13). They suggested that when studio-based learning used in conjunction with application development with smartphones, is an effective pedagogy for an introductory programming course.

Reference [12] introduced Game-themed programming (GTP) in the programming education to teach abstract programming concepts to the students by exploring small game applications. They concluded that success rates in GTP based classes were higher than other traditional classes in programming education. Reference [13] prepared and introduced a game (RoboBUG) to teach debugging in programming to novices. The results of the study show a positive impact of game-based learning on novices learning process.

\section{$3 \quad$ Research Questions}

It is evident from the previous section that different learning systems such as Elearning, M-learning and game-based learning can play an important role in programming education. Therefore, in this study, we prepared and offered the PROBSOL application in three different learning systems ('E-PROBSOL, M-PROBSOL, and PROSOLVE' game) to novice programmers in the introductory programming course. We purpose research questions to guide the study and to determine the impact of these three different learning systems on novice programmers.

The research questions being addressed in this study are as follows:

RQ1: what is the impact on the perception of genders after introducing the Elearning in the programming education?

RQ2: what is the impact on the perception of genders after introducing the $M$ learning in the programming education?

RQ3: what is the impact on the perception of genders after introducing the gamebased learning in the programming education?

\section{4 'PROBSOL' Applications}

A web-based application ('PROBSOL') is developed and offered in the introductory programming (IP) course to enhance problem solving skills of novice programmers. The application is based on pseudo-code technique and it covers most of the teaching topics of the IP course. Questions related to different topics are embedded in the application. Figure 1 shows the interface of the 'E-PROBSOL' application. 


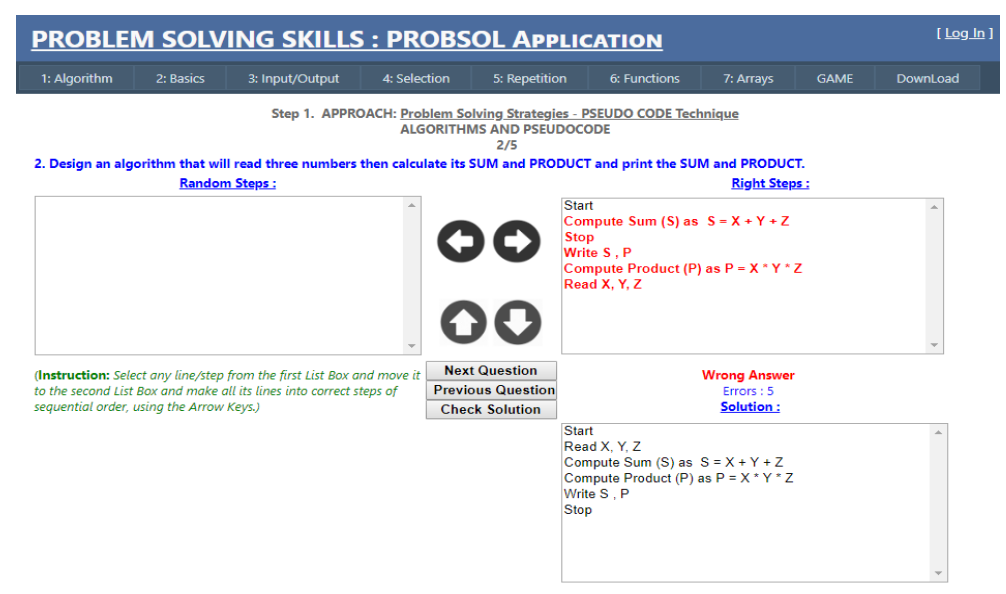

Fig. 1. Interface of the 'E-PROBSOL' application

Three list boxes (Random, Right and Solution steps) are used in the application. Random steps of the given problem statement are listed in the Random list box. A user selects and moves the appropriate step from the Random list box to the Right step box by clicking on the Right arrow button as shown in figure 1 . The correct solution of the given problem statement can be accessed from the Solution list box after clicking the Check Solution button. The application counts the wrong steps in the users' solution and these wrong steps are shown in red color in Right list box as shown in figure 1.

The 'PROBSOL' application is also offered as a mobile app ('M-PROBSOL') for novice programmers in the IP course as shown in figure 2. The main purpose is to facilitate the learning process of the IP course. The 'M-PROBSOL' app is available in the Google store. Moreover, a user can download the app from the following web site (www.mserves.com). The app provides the same functions and features as in the EPROBSOL application.

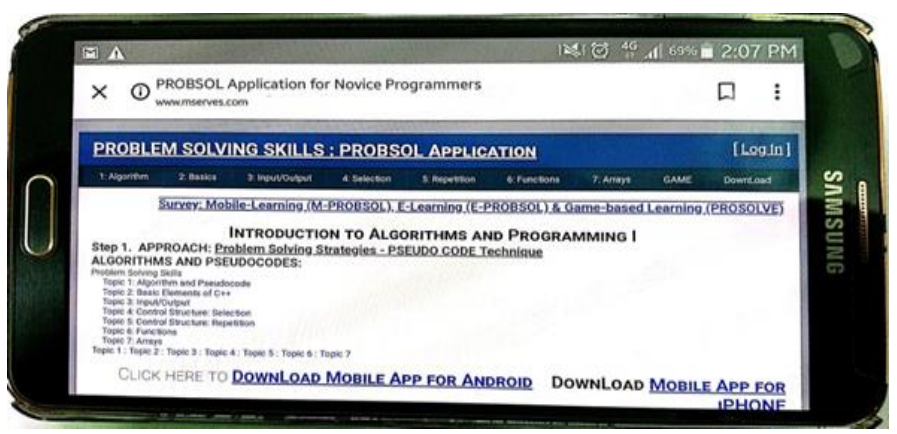

Fig. 2. Interface of the 'M-PROBSOL' application 
The 'PROBSOL' application is also offered as a 'PROSOLVE' game with a few modifications as shown in figure 3 . The game consists of two list boxes (Random and Solution steps). A user provides the right solution of the given problem statement in the Random list box by clicking up or down arrows buttons. The user can get the right solution by clicking 'Get Points' button. Moreover, the game compares the user solution provided in the Random list box with the correct solution provided in the Solution list box and award points. The errors in the users' solution are depicted in red color in Random steps list box as shown in figure 3.

The game comprises of seven levels and different teaching topics of the IP course are covered in each level. A user can win medal (bronze, silver or gold) based on the points earned in the game. Furthermore, the user can win a cup depends on the total points earned in the game.

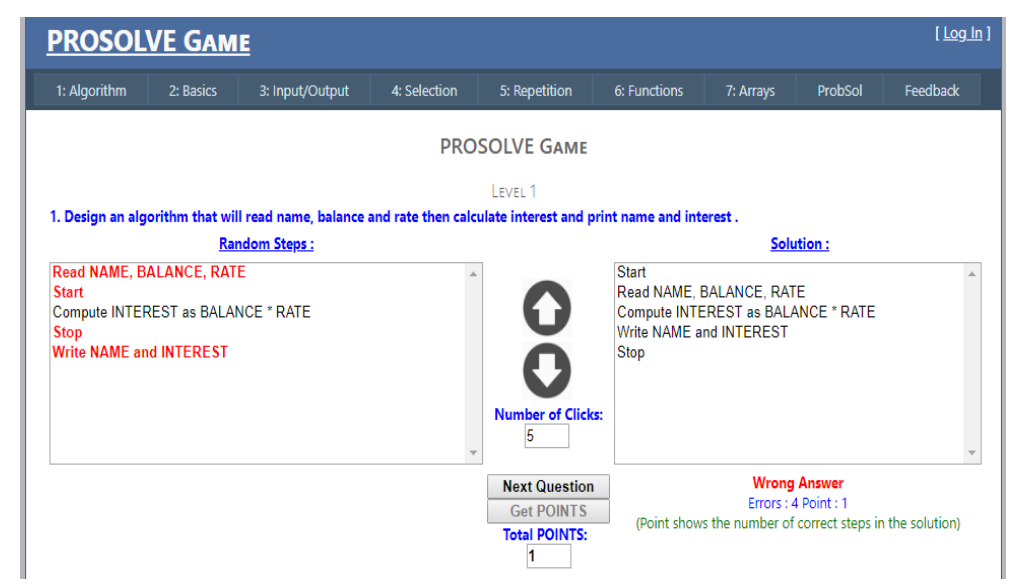

Fig. 3. Interface of the 'PROSOLVE' game

\section{$5 \quad$ Research Methodology}

The research questions were investigated by conducting a survey with students of the IP course after introducing the 'E-PROBSOL, M-PROBSOL, and PROSOLVE' game. 204 students participated in the survey including 87 male (42.6\%) and 117 female $(57.4 \%)$.

The survey has four parts and consists of 38 closed -ended questions. The first part of the survey consists of five demographic questions (gender, age, major, programming experience, and preferences among E-learning, M-learning and Game-based learning). The second part includes eleven questions related to E-learning ('EPROBSOL'). The third part of the survey covers eleven questions related to $\mathrm{M}$ learning ('M-PROBSOL'). The last part of the survey consists of eleven questions related to the 'PROSOLVE' game. The same set of questions are included in the second, third and fourth sections of the survey to obtain students' perceptions and preferences among 'E-PROBSOL, M-PROBSOL, and PROSOLVE' game in the teaching 
and learning process of the IP course. A five point Likert scale ( $1=$ strongly disagree to $5=$ strongly agree) is used for questions related to the second, third and fourth parts of the survey. The data was collected from the students after obtaining an ethical approval from the college. Students' participation was optional and volunteer in the survey. Moreover, data collection was anonymous in the survey.

\section{Results}

This section describes the results of this study. The research questions were explored by analyzing the responses of students in the survey.

The research questions were explored by using a statistical method. The mean values for each question were compared by gender.

a) Demographic details

The demographic details of the respondents are as follows:

- $53.9 \%$ respondents are enrolled in the Information Systems major, compared to $31.4 \%$ from Computer Science and $14.7 \%$ from Software Engineering.

- $78.9 \%$ respondents are between 18 to 22 years old, compared to $13.2 \%$ between 23 to 28 years, and $7.8 \%$ from above 28 years.

- Most of the respondents (57.4\%) were female compared to $42.6 \%$ male.

- The majority of the respondents $(52.9 \%)$ do not have any prior programming experience.

- $64.7 \%$ respondents prefer M-learning, compared to $19.1 \%$ prefer E-learning, and 16.2 prefer Game-based learning.

b) E-Learning ('E-PROBSOL')

This section addresses the first research question, which is:

RQ1: what is the impact on the perception of genders after introducing the $E$ learning in the programming education?

Respondents' perception after introducing the 'E-PROBSOL' in the IP course for understanding programming concepts is shown in figure 4 . Moreover, figure 4 shows a comparison of mean values by gender for a set of questions. 


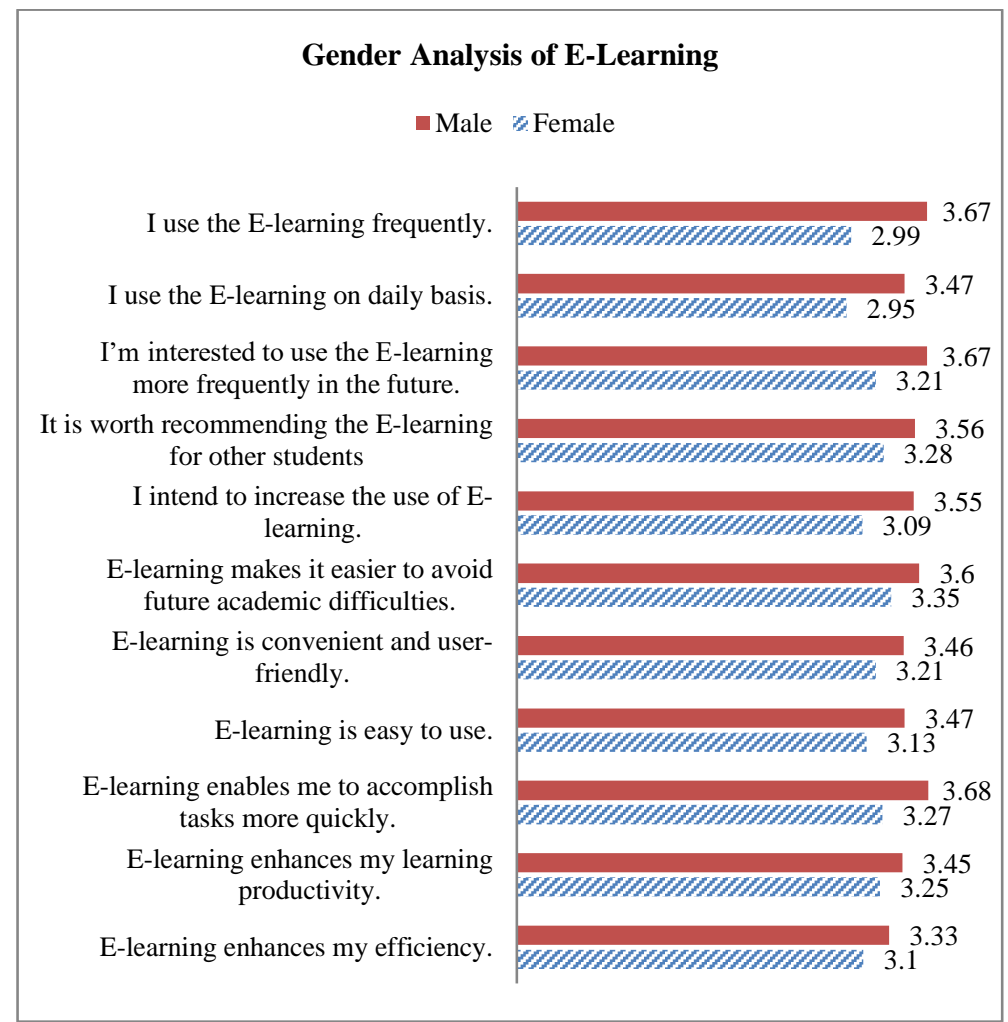

Fig. 4. E-learning (E-PROBSOL)

Figure 4 depicts that male students show more positive responses compared to female students in all the questions related to the 'E-PROBSOL' in the teaching and learning process of the IP course.

\section{c) M-Learning ('M-PROBSOL')}

This section explores the second research question which is:

RQ2: what is the impact on the perception of genders after introducing the $M$ learning in the programming education?

Figure 5 shows the respondents perceptions after introducing the 'M-PROBSOL' in the IP course. 


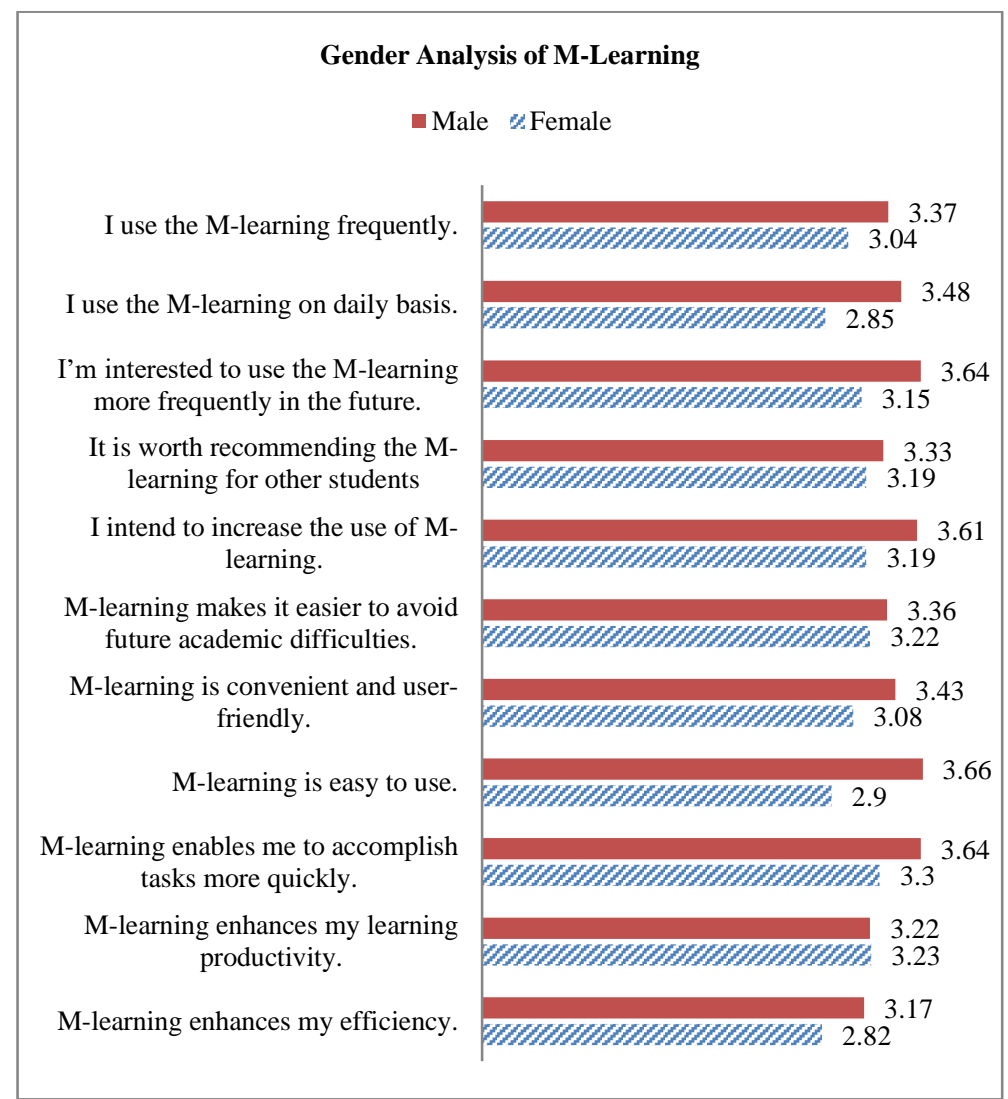

Fig. 5. M-learning (M-PROBSOL)

Likewise in E-PROBSOL, figure 5 shows that male students depicts more positive responses compared to female students in most of the questions related to ' $\mathrm{M}$ PROBSOL' except 'M-learning enhances my learning productivity' where female students depict slightly better response $(0.01 \%)$ than male students.

\section{d) Game-based Learning ('PROSOLVE')}

This section addresses the first research question which is:

RQ3: what is the impact on the perception of genders after introducing the gamebased learning in the programming education?

Respondents' perception after introducing the 'PROSOLVE' in the IP course is shown in figure 6. 


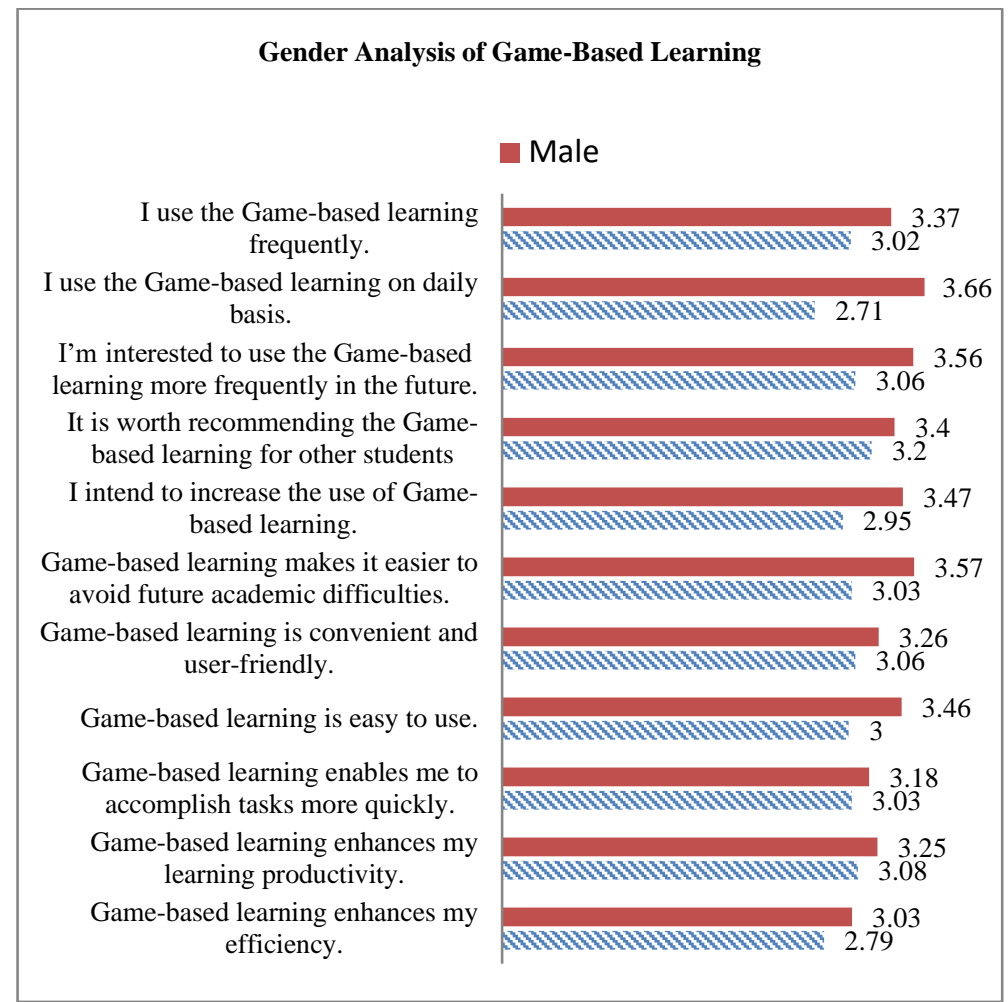

Fig. 6. Game-based learning ('PROSOLVE')

The mean values of male students are better for all the questions compared to female students in this part of the survey.

\section{Discussion}

The result of the students' survey depicts that both female and male students appreciated the 'E-PROBSOL, M-PROBSOL and PROSOLVE' game in the teaching and learning process of the IP course. All the three applications helped novices to understand the precise concepts of programming domain. The applications focus on students' cognitive engagement and gain in programming. Furthermore, the applications help in developing affective engagement of students in the course. This finding is consistent with the reference [14] who also advocated that E-learning and Mlearning promoted problem solving skills in programming education.

The survey results show that male students depict more positive response than female students about incorporating all the three application ('E-PROBSOL, MPROBSOL and PROSOLVE' game) in the teaching and learning process of the IP course. Reference [15] discussed that it may be due to lack of self-confidence in female students compared to male students. This finding is also consistent with [16] 
who concluded after introducing a new teaching approach in programming education that male students are more confident compared to female students in learning programming.

All the three applications promote algorithmic thinking in the course. Novices have to devise the solution of the given problem statement by using pseudo-code technique (problem solving strategy) before start writing the code in any programming language. This process promotes deep-learning of the programming domain among novice programmers. This finding is consistent with [17][18] who introduced a new teaching approach in the IP course to promote algorithmic thinking. Moreover, references [19][20] advocated that game-based learning promoted algorithmic thinking in programming education.

Both female and male students perceived that all the three applications ('EPROBSOL, M-PROBSOL and PROSOLVE' game) are user-friendly and easy to use. The applications enabled students to accomplish tasks more quickly and enhanced their learning productivity. Moreover, the applications enhanced students' efficiency and they used applications on daily basis. Students preferred to use E-learning, Mlearning and game-based learning more frequently in the future in their learning process. Furthermore, both female and male students recommended E-learning, Mlearning and game-based learning for other students in their learning process. This process promotes students' affective engagement, cognitive engagement and gain in programming domain. This finding is consistent with [21][22].

All the three applications ('E-PROBSOL, M-PROBSOL and PROSOLVE' game) discourage the presentation style which promotes programming shortcut [23] ('Problem statement $\rightarrow$ Codes') and encourage the presentation style ('Problem statement $\rightarrow$ Solution plan $\rightarrow$ Codes') which promotes deep learning in programming education. This finding is consistent with [24][25] who introduced the four stages of the ADRI approach in the programming education to discourage programming shortcut.

All the three applications ('E-PROBSOL, M-PROBSOL and PROSOLVE' game) provide an opportunity for students to practice programming concepts by choosing a mode of instruction based on their interest. If the student like E-learning can use 'EPROBSOL', if like M-learning can use 'M-PROBSOL', and if like game-based learning can use 'PROSOLVE' game. This process promotes affective engagement of students in the course. This finding is consistent with [26][27][28].

Most of the teaching topics of the IP course are covered in all the three applications. Novices practice problem solving strategies throughout the semester which promotes deep learning of the programming concepts. Reference [29] discussed that 'practice is considered an important step in grasping the precise concepts of computer programming for novices' (p. 1).

All the three applications ('E-PROBSOL, M-PROBSOL and PROSOLVE' game) also support instructors to incorporate different teaching strategies to engage students in the learning process of programming education. Moreover, instructors can use all the three applications as an additional teaching tool in the teaching and learning process of programming education. The applications also provide a question bank to the instructors. Reference [30] discussed that 'the technology integrated tools emphasis on student interest in order to develop their academic performance.' (p. 2). 


\section{Conclusion}

Gender differences were examined in the introductory programming (IP) course after introducing the 'PROBSOL' application as three different learning systems (Elearning, M-learning and game-based learning) in the teaching and learning process of the course. All the three applications are web-based and easy to use. Moreover, they are based on pseudo-code technique. Most of the teaching topics of the IP course are covered in all three applications.

A survey was conducted with the IP students to determine their perception about all the three applications in the IP course. Gender differences were determined by comparing both female and male students' responses for each question in the survey. The comparison shows that male students were more satisfied with all the three applications compared to female students. It may be due to that male students are more self-confident compared to female students [15].

All the three applications promote algorithmic thinking, discourage programming shortcut, and enhance students' affective engagement, cognitive engagement and gain in the IP course. Both female and male students perceived that all the three applications are user-friendly, enabled them to accomplish tasks more quickly, and enhanced their learning productivity. Instructors can also use all the three applications as an additional teaching tool in the teaching and learning process of programming education. Overall, both male and female students appreciated all the three applications in the teaching and learning process of the IP course.

\section{$9 \quad$ References}

[1] R., Mathew, S.I., Malik, and R.M. Tawafak, "Teaching Problem Solving Skills using an Educational Game in a Computer Programming Course", Informatics in Education, Vol. 18 No. 2, pp. 359-373, https://doi.org/10.15388/infedu.2019.17

[2] S.M., Shuhidan, "Probing the minds of novice programmers through guided learning", PhD thesis, RMIT University, Australia, 2012

[3] S.I., Malik, and J., Coldwell-Neilson, "Impact of a new teaching and learning approach in an introductory programming course", Journal of Educational Computing Research, SAGE, vol. 55, No. 6, pp. 789-819, 2017, https://doi.org/10.1177/0735633116685852.

[4] L.E., Winslow, "Programming pedagogy - a psychological overview", ACM SIGCSE Bulletin, Vol. 28, No. 3, pp.17-22, 1996. https://doi.org/10.1145/234867.234872

[5] S.I. Malik., R. Mathew M.M. Hammood, "PROBSOL: A Web-Based Application to Develop Problem-Solving Skills in Introductory Programming”. In: Al-Masri A., Curran K. (eds) Smart Technologies and Innovation for a Sustainable Future. Advances in Science, Technology \& Innovation (IEREK Interdisciplinary Series for Sustainable Development). Springer, 2019, pp 295-302, https://doi.org/10.1007/978-3-030-016593_34

[6] K.M.Y. Law, V.C.S. Lee, and Y.T. Yu, "Learning motivation in e-learning facilitated computer programming courses”, Computers \& Education, Volume 55, Issue 1,2010, pp. 218-228. https://doi.org/10.1016/j.compedu.2010.01.007

[7] S.I. Malik, "Role of ADRI model in teaching and assessing novice programmers", $\mathrm{PhD}$ thesis, Deakin University, 2016, hdl.handle.net/10536/DRO/DU:30088862 
[8] S.I., Malik, and J., Coldwell-Neilson, “A model for teaching an introductory programming course using ADRI", Education and Information Technologies, Springer, vol. 22, issue 3, pp. 1089-1120, https://doi.org/10.1007/s10639-016-9474-0

[9] S., Iqbal, M., Chowdhury, and O.K., Harsh, "Mobile devices supported learning for novice programmers", Proceeding of the $2^{\text {nd }}$ international conference on E-learning and Etechnologies in education, IEEE, Poland, 2013, pp. 277-282. https://doi.org/10.1109/icelete.2013.6644388

[10] D., Mcphee, P., Thomas, M., Ware, and N., Thomas, "An investigation into the effectiveness of the use of m-learning in the teaching of multimedia to first year university students", International Journal of Emerging Technologies in Learning, Vol. 1, No. 1, 2006

[11] S., Reardon, and B. Tangney, "Smartphones, Studio-based learning, and scaffolding: Helping novice learn to program", Transaction of Computer Education, Vol. 14, No. 4, 2014, ACM. https://doi.org/10.1145/2677089

[12] K., Sung, C., Hillyard, R.L., Angotti, M.W., Panitz, D.S.,Goldstein, and J. Nordlinger, "Game-Themed Programming Assignment Modules: A Pathway for Gradual Integration of Gaming Context Into Existing Introductory Programming Courses", IEEE Transactions on Education, Vol. 54, No. 3, 2011, pp. 416-427. https://doi.org/10.1109/te.2010.2064315

[13] M.A., Miljanovic, "RoboBUG: A game based approach to learning debugging techniques", Master thesis, accessed on October, 07, 2015, ir.library.dcuoit.ca/handle/10155/536

[14] S.I., Malik, R., Mathew, R., Al-Nuaimi, A., Al-Sideiri, J. Coldwell-Neilson, "Learning problem solving skills: Comparison of E-learning and M-learning in an introductory programming course". Education and Information Technologies, 24, 2779-2796, 2019, https://doi.org/10.1007/s10639-019-09896-1

[15] A. Funke, M. Berges, A. Mühling, P. Hubwieser, "Gender Differences in Programming: Research Results and Teachers' Perception”, Proceedings of the 15th Koli Calling Conference on Computer Education Research, 2015, ACM, Finland. https://doi.org/10. $\underline{1145 / 2828959.2828982}$

[16] S.I. Malik, and J. Coldwell-Neilson, "Gender differences in an introductory programming course: New teaching approach, students' learning outcomes, and perceptions", Education and Information Technologies, Springer, 2018, https://doi.org/10.1007/s10639-018-9725-3

[17] S.I. Malik, M. Shakir, A. Elbow, and M.W. Ashfaque, "Promoting algorithmic thinking in an introductory programming course", International Jounral of Emerging Technologies in Education, Vol 14, No. 1, 2019. https://doi.org/10.3991/ijet.v14i01.9061

[18] S.I. Malik, R., Mathew, R.M., Tawafak, and I., Khan, "gender difference in perceiving algorithmic thinking in an introductory programming course", In proceedings of the 11th International Conference on Education and New Learning Technologies, 2019, pp. 82468254. https://doi.org/10.21125/edulearn.2019.2042

[19] G. Kiss, and Z. Arki, "The influence of game-based programming education on the algorithmic thinking". Procedia - Social and Behavioral Sciences, Vol. 237, Issue 21, 2017, pp. 613-617. https://doi.org/10.1016/j.sbspro.2017.02.020

[20] H. Chih-Chao, and W. Tzone-I, "Applying game mechanics and student-generated questions to an online puzzle-based game learning system to promote algorithmic thinking skills", Computers \& Education, 2018, Vol. 121, pp. 73-88. https://doi.org/10.1016/ j.compedu.2018.02.002

[21] R. M., Tawafak, S. I., Malik, and G., Alfarsi, "Development of Framework from Adapted TAM with MOOC Platform for Continuity Intention”, International Journal of Advanced Science and Technology, 2020, Vol 29, Issue 1 
[22] R. M., Tawafak, A. B., Romli, R. B. A., Arshah, and S. I., Malik, "Framework design of university communication model (UCOM) to enhance continuous intentions in teaching and e-learning process". Education and Information Technologies, 2020, pp. 817-843, https://doi.org/10.1007/s10639-019-09984-2.

[23] M. Webster, Overview of programming and problem solving, Merriam-Webster's Collegiate Dictionary, Tenth Edition, 1994, retrieved on July15, 2013: computerscience.jbpub.com/vbnet/pdfs/momillan01.pdf

[24] S.I. Malik, "Improvements in introductory programming course: action research insights and outcomes", Systemic Practice and Action Research, DOI: 10.1007/s11213-018-9446y, 2018, Springer. https://doi.org/10.1007/s11213-018-9446-y

[25] S., Iqbal, and O.k., Harsh, "A self review and external review model for teaching and assessing novice programmers", International Journal of Information and Education Technology, Vol. 3, No. 2, 2013, pp. 120-123. https://doi.org/10.7763/ijiet.2013.v3.247

[26] R. M., Tawafak, A., Romli, S. I., Malik, M., Shakir, and G., Alfarsi, "A systematic review of personalized learning: Comparison between E-learning and learning by coursework program in Oman", International Journal of Emerging Technologies in Learning (iJET), (2019), Vol. 14, No. 9, pp. 93-104. https://doi.org/10.3991/ijet.v14i09.10421

[27] G., Alfarsi, H., Sulaiman, R. M., Tawafak, S. I., Malik, J., Jabbar, and A., Alsidiri, “A Study of Learning Management System with E-Learning", International Journal of Advanced Science and Technology, 2020, Vol. 29, Issue 3, pp. 4884- 4890

[28] R.M., Tawafak, A., Alsidiri, G., Alfarsi, M., Alnuaimi, S. I., Malik, and J., Jabbar, "Elearning Vs. Traditional Learning for Learners Satisfaction”, International Journal of Advanced Science and Technology, 2020, Vol. 29, Issue 3, pp. 388-397

[29] S.I. Malik, "Enhancing practice and achievement in introductory programming using an ADRI editor", In Proceedings of the IEEE International Conference on Teaching, Assessment and Learning for Engineering, 2016, pp. 32-39, IEEE, Thailand, 7-9 December, https://doi.org/10.1109/tale.2016.7851766

[30] R.M. Tawafak, A.B. Romli, R.B.A. Arshah, and R.A.S. Almaroof, "Assessing the Impact of Technology Learning and Assessment Method on Academic Performance: Review paper”, Eurasia Journal of Mathematics, Science and Technology Education, 2018, Vol. 14, No. 6, pp. 2241-2254. https://doi.org/10.29333/ejmste/87117.

\section{Authors}

Sohail Iqbal Malik has been working as a head of department and an Assistant Professor at Information Technology Department, Buraimi University College, Oman since February 2007. He obtained his Ph.D. in Computer Science from Deakin University, Australia. His research interest includes: Algorithmic thinking, Computer Education, Technology in Education, and E-Learning.

Mostafa Al-Emran is an Assistant Professor in the Department of Information Technology at Al Buraimi University College, Oman. He obtained his Ph.D. degree in Computer Science from Universiti Malaysia Pahang. He received the MSc degree in Informatics from The British University in Dubai with a distinction level along with the top Academic Excellence Award and the BSc degree with honors in Computer Science from Al Buraimi University College. He has published over 55 research articles in highly reputed journals such as Computers \& Education, Computers in Human Behavior, International Journal of Information Management, IEEE Access, Interactive 
Learning Environments, Technology in Society, Journal of Educational Computing Research, and International Journal of Engineering Education, among many others. Most of his publications were indexed under the ISI Web of Science and Scopus. He is a certified recognized reviewer by several leading journals in Elsevier. His current research interests include mobile learning, knowledge management, technology acceptance, and wearable technology.

Roy Mathew is currently working as Software Engineering Coordinator and an Assistant Professor in Buraimi University College, Oman. His Research interests include Data Mining and Knowledge Management, Database Management Systems, Web Site Designing, Cloud Computing, E-Learning, Algorithmic Development for Novices.

Ragad Moufaq Tawafak received the bachelor's degree with a focus on expert system of bacteria classification project and the M.Sc. degree (Hons.) in computer science from Al-Mousel University, Iraq, with a focus on hybrid neural network and genetic algorithms. She is currently pursuing the Ph.D. degree in computer science with the University Malaysia Pahang. She was with the Software Engineering Department, Al-Mustansryia University, Iraq, for four years. She was with the Oman College of Management and Technology for two years. She has been a Lecturer with the Information Technology Department, Buraimi University College, Oman, for over 12 years. Most of her publications were indexed under Scopus. Her current research interests include e-learning, blended learning, Image Processing, technology adoption and acceptance, and academic performance.

Ghaliya Alfarsi is currently working as a lecturer at the Department of Information Technology, Al Buraimi University College, Oman. She obtained her master degree in Computer Science from Sohar University, Oman. Her research expertise's are in knowledge management, integrated system, e-learning, m-learning and image processing.

Article submitted 2020-03-31. Resubmitted 2020-05-07. Final acceptance 2020-05-08. Final version published as submitted by the authors. 